\title{
Dissection of a dilated autograft root
}

\author{
Loes M. A. Klieverik, MD, ${ }^{a}$ Johanna J. M. Takkenberg, MD, PhD, ${ }^{a}$ Brigitte C. J. Elbers, MD, ${ }^{a}$ Frans B. S. Oei, MD, PhD,
} Lex A. van Herwerden, MD, PhD, ${ }^{b}$ and Ad J. J. C. Bogers, MD, PhD, ${ }^{a}$ Rotterdam and Utrecht, The Netherlands



lthough the Ross procedure is still the preferred operation for aortic root replacement in children and young adults, the number of reoperations for autograft root dilatation after the Ross procedure has increased in recent years. ${ }^{1-4}$

In our ongoing prospective clinical and echocardiographic follow-up study of 146 consecutive patients undergoing a Ross procedure with the root replacement technique since 1988, 29 patients have undergone pulmonary autograft reoperations to date. In most cases valve cusps are intact, but because of progressive autograft root dilatation coaptation of the cusps is lost and aortic valve regurgitation occurs.

We report a patient who presented with severe aortic regurgitation due to asymmetric autograft dilatation caused by a dissection in the noncoronary sinus of Valsalva.

\section{Clinical Summary}

A 50-year-old woman with a bicuspid native aortic valve, symptomatic moderate aortic regurgitation, and a dilated left ventricle with good systolic function returned for reoperation 9 years after undergoing a modified Ross procedure with the root replacement technique. The patient had symptoms of fatigue and dyspnea on exertion. Echocardiographic examination 4 months before the reoperation showed severe aortic and pulmonary regurgitation and a dilated left ventricle with an end-diastolic diameter of $62 \mathrm{~mm}$ and end-systolic diameter of $48 \mathrm{~mm}$. Furthermore, the ascending neoaorta was severely dilated with a diameter of $54 \mathrm{~mm}$.

At reoperation the neoaortic root showed asymmetric dilatation with bulging of the noncoronary sinus of Valsalva. After the neoaortic root was opened, a large transverse intimal tear that extended into the media was seen in the noncoronary sinus of the autograft root, causing the asymmetric dilatation (Figure 1). This tear was limited to the autograft wall and had no connection with the distal suture line. The autograft valve leaflets appeared normal. The pulmonary autograft was replaced with a mechanical valve conduit of $25 \mathrm{~mm}$ (St Jude Medical Inc, St Paul, Minn), and the pulmonary allograft was replaced with a cryo-

From the Department of Cardiothoracic Surgery, Erasmus Medical Center, ${ }^{\text {a }}$ Rotterdam, The Netherlands; and the Department of Cardiothoracic Surgery, University Medical Center, ${ }^{\mathrm{b}}$ Utrecht, The Netherlands.

Address for reprints: Loes M. A. Klieverik, MD, Department of Cardiothoracic Surgery, Bd 571, Erasmus University Medical Center Rotterdam, PO Box 2040, 3000 CA Rotterdam, The Netherlands (E-mail: 1.klieverik@erasmusmc.nl).

J Thorac Cardiovasc Surg 2007;133:817-8

$0022-5223 / \$ 32.00$

Copyright () 2007 by The American Association for Thoracic Surgery

doi:10.1016/j.jtcvs.2006.11.006 preserved pulmonary allograft. The procedure and postoperative course were uneventful.

Microscopic examination revealed a viable pulmonary autograft valve and neoaortic wall. The valve leaflets showed intimal hyperplasia on the ventricular side, and intimal and adventitial fibrosis of the neoaortic wall was present. In addition, cystic medial necrosis with fragmentation, loss of elastic fibers, and deposition of mucopolysaccharides were found throughout the media. The tear of the neoaortic wall extended beyond the intima into the media. The defect was already covered with mucopolysaccharides, but without neo-endothelization, suggesting that this tear was at least a few months old but no more than 1 year old.

\section{Discussion}

In most of the 29 reoperative autograft cases at our institution, progressive dilatation of the neoaortic root resulting in aortic regurgitation necessitated reoperation. Histologic findings in the explanted autografts comprised cystic medial necrosis with fragmentation, loss of elastic fibers, and deposition of mucopolysaccharides. ${ }^{1}$ The current case is different from the other reoperative autograft cases in our experience and raises concern for the following reasons.

The asymmetric root dilatation was a result of an intimal tear of the noncoronary sinus extending into the media, causing a limited dissection that potentially could lead to a free wall rupture. The autograft dissection presented 9 years after the initial Ross procedure. Luciani and colleagues ${ }^{5}$ reported an autograft dissection 8.5 years after the initial Ross procedure. This dissection also occurred in the noncoronary sinus, suggesting the possible vulnerability of this specific location to rupture. This intima rupture was in a longitudinal direction and did not interfere with any of the suture lines (G. B. Luciani, MD, personal communication, 2005). Aortic dissection is usually characterized by longitudinal cleavage of the aortic media by a dissecting column of blood, which was not present in the explanted autograft root described by Luciani and colleagues or in our presented case.

A new observation emerging from our report is that progressive dilatation of the neoaortic wall makes it increasingly weak and prone to rupture late after the initial Ross procedure.

Furthermore, the dissection in the neoaortic wall existed for months without any clinical signs. Because of the limited size of the intimal tear and denervation of the neoaortic root, the patient did not have pain, and a potentially lethal complication is hard to recognize without careful echocardiographic monitoring.

This report illustrates that the pulmonary autograft not only can show dissection but also may rupture, causing a potentially lifethreatening complication. High awareness of potential neoaortic root dissection is required in all patients with autograft roots, particularly those patients whose autograft root gradually dilates over the years. 




Figure 1. Explanted autograft root with a transverse dissection of the noncoronary sinus. The valve leaflets appear normal. A, Proximal flap of the dissection; microscopic overview (inserted picture A, hematoxylin-eosin, $\times 40)$ shows abrupt disruption of the fibrosed intima, the dissection flap, and a bare media without signs of neoendothelization. B, Dissection area of the neoaortic wall; microscopic detail (inserted picture $B$, hematoxylin-eosin, $\times 100$ ) shows only the typical fragmented autograft media without endothelial lining. C, Distal anastomosis between autograft root and native ascending aorta; inserted picture $\mathrm{C}$ shows the microscopic overview (hematoxylineosin, $\times 100)$ in this area.

Therefore, continuing and frequent systematic echocardiographic surveillance of this patient group is highly recommended in the second decade after the operation.

\section{References}

1. Takkenberg JJ, Zondervan PE, van Herwerden LA. Progressive pulmonary autograft root dilatation and failure after Ross procedure. Ann Thorac Surg. 1999;67:551-3; discussion 553-4.

2. Kouchoukos NT, Masetti P, Nickerson NJ, Castner CF, Shannon WD, Davila-Roman VG. The Ross procedure: long-term clinical and echo- cardiographic follow-up. Ann Thorac Surg. 2004;78:773-81; discussion 773-81.

3. Luciani GB, Casali G, Favaro A, Prioli MA, Barozzi L, Santini F, et al. Fate of the aortic root late after Ross operation. Circulation. 2003; 108(Suppl 1):II61-7.

4. Brown JW, Ruzmetov M, Fukui T, Rodefeld MD, Mahomed Y, Turrentine MW. Fate of the autograft and homograft following Ross aortic valve replacement: reoperative frequency, outcome, and management. $J$ Heart Valve Dis. 2006;15:253-9; discussion 259-60.

5. Luciani GB, Favaro A, Viscardi F, Bertolini P, Mazzucco A. Valvesparing root replacement for pulmonary autograft dissection late after the Ross operation. J Thorac Cardiovasc Surg. 2004;128:753-6. 